\title{
STRUKTUR KOMUNITAS TUMBUHAN PAKU (PTERIDOPHYTA) DI KAWASAN HUTAN KUSU-KUSU KECAMATAN NUSANIWE DAN SOYA KECAMATAN SIRIMAU KOTA AMBON SEBAGAI SUMBANGAN ILMIAH BAGI MATA KULIAH EKOLOGI TUMBUHAN
}

\author{
Jeanne L. Maalalu' ${ }^{1}$, D. Rumahlatu² \\ ${ }^{1}$ Alumi Program Studi Pendidikan Biologi \\ ${ }^{2}$ Staf Pengajar Program Studi Pendidikan Biologi \\ E-mail: dominggus_amq@yahoo.co.id
}

\begin{abstract}
Background: Nail plants (Pteridophyta) are cormus plants whose bodies can be clearly distinguished between roots, stems, and leaves. However, ferns cannot produce seeds because they breed with spores. Nail plants are divided into 4 classes, namely (1) Psilophytinae (ancient nail); (2) Lycopodiinae (wire nail); (3) Equisetinae (horsetail); and (4) Filicinae (true nail). Community structure is a concept that studies species composition or composition and its abundance in a community.

Method: This research is a quantitative descriptive study to reveal information about the community structure of ferns. The study was conducted on July 18, 2018 - August 18, 2018.

Results: The ferns found in the Kusu-Kusu forest area were 10 species and the Soya region as many as 20 species. Overall the types of ferns found in the two study locations were grouped into 2 classes, namely Filicinae / Pteropsida (true nail) and Lycopodiinae (wire nails). The Filicinae / Pteropsida class has a greater number of species, both in the Kusu-Kusu forest area (8 species) and the Soya forest area (13 species). The Lycopodiinae class has a smaller number of species, both in the Kusu-Kusu forest area (2 types), and the Soya forest area (7 species).

Conclusions: 10 ferns were found in the Kusu-Kusu Sereh forest area in Nusaniwe Subdistrict, while in the Soya District of Sirimau District there were 20 species.
\end{abstract}

Keywords: Nail plants (pteridophyta), community structure, and forest area.

\begin{abstract}
Abstrak
Latar Belakang: Tumbuhan paku (Pteridophyta) adalah tumbuhan kormus yang tubuhnya dengan nyata dapat dibedakan antara akar, batang, dan daun. Akan tetapi tumbuhan paku belum dapat menghasilkan biji karena berkembangbiak dengan spora. Tumbuhan paku terbagi menjadi 4 kelas, yaitu (1) Psilophytinae (Paku purba); (2) Lycopodiinae (Paku kawat); (3) Equisetinae (Paku ekor kuda); dan (4) Filicinae (Paku sejati). Struktur komunitas merupakan suatu konsep yang mempelajari susunan atau komposisi spesies dan kelimpahannya dalam suatu komunitas.

Metode: Penelitian ini merupakan penelitian deskriptif kuantitatif untuk mengungkapkan informasi tentang struktur komunitas tumbuhan paku. Penelitian dilaksanakan pada tanggal 18 Juli $2018-18$ Agustus 2018.

Hasil: Tumbuhan paku yang ditemukan di kawasan hutan Kusu-Kusu sebanyak 10 jenis dan kawasan Soya sebanyak 20 jenis. Secara keseluruhan jenis tumbuhan paku yang ditemukan di kedua lokasi penelitian tersebut dikelompokan menjadi 2 kelas yaitu Filicinae/Pteropsida (paku sejati) dan Lycopodiinae (paku kawat). Kelas Filicinae/Pteropsida memiliki jumlah jenis yang lebih banyak, baik pada kawasan hutan Kusu-Kusu (8 jenis) dan kawasan hutan Soya (13 jenis). Adapun kelas Lycopodiinae memiliki jumlah jenis yang lebih sedikit, baik pada kawasan hutan Kusu-Kusu (2 jenis), dan kawasan hutan Soya (7 jenis).

Kesimpulan: Tumbuhan paku yang ditemukan di kawasan hutan Kusu-Kusu Sereh Kecamatan Nusaniwe sebanyak 10 jenis, sedangkan di kawasan hutan Soya Kecamatan Sirimau sebanyak 20 jenis.
\end{abstract}

Kata Kunci: Tumbuhan paku (pteridophyta), struktur komunitas, kawasan hutan. 


\section{PENDAHULUAN}

Indonesia adalah negara tropis yang mempunyai luas daratan sebesar 193 juta hektar $(24,7 \%$ dari luas total wilayah) (Sandi $d k k$. 2015). Di atas daratan tersebut, terdapat hutan seluas 143,9 juta hektar (75\% dari luas daratan) (Suraidi $d k k$., 2012). Dengan luas hutan yang begitu besar tersebut, maka Indonesia dikenal sebagai negara dengan kekayaan keanekaragaman tumbuh-tumbuhan terbesar ketiga di dunia (Sandi $d k k, 2015$ ). Paku (Pteridophyta) merupakan salah satu contoh tumbuhan yang melimpah di hutan Indonesia.

Paku (pteridophyta) merupakan tumbuhan kormus berspora karena sudah memiliki rhizoid, batang, dan daun (Tjitrosoepomo, 2011). Rhizoid sudah berkembang menjadi bentuk akar yang sebenarnya, batang bercabang-cabang, dan susunan daun yang umumnya membentuk bangun sayap (menyirip) dan pada bagian pucuk terdapat bulu-bulu (Yudianto dan Suroso, 2007). Tjitrosoepomo (2011) menjelaskan bahwa tumbuhan paku memiliki peranan perting secara ekologi dan ekonomis. Secara ekologi, tumbuhan paku bermanfaat dalam memelihara ekosistem hutan karena dapat menyuburkan tanah, yaitu jenis Azolla pinnata yang bersimbiosis dengan Anabaena (alga biru) sehingga dapat mengikat unsur nitrogen dari udara. Adapun secara ekonomis, tumbuhan paku dimanfaatkan sebagai bahan obat, yaitu jenis Equisetum (paku ekor kuda) untuk memperlancar seni, sebagai bahan sayuran, yaitu jenis Marsilea (semanggi), dan sebagai tanaman hias, yaitu jenis Adiantum (suplir). Tjitrosoepomo (2011) menjelaskan bahwa tumbuhan paku dapat dikelompokkan ke dalam empat kelas yaitu Psilophytinae (paku purba), Lycopodiinae (paku rambat atau paku kawat), Equisetinae (paku ekor kuda), dan Filiciane (paku sejati) yang memiliki banyak jenis dan hidup bersama membentuk komunitas.

Dalam komunitas dapat dikaji keberadaan beranekaragam jenis tumbuhan paku yang hidup bersama. Salah satu ciri khas dari tingkatan komunitas tumbuhan paku adalah keanekaragaman jenis. Komunitas tumbuhan paku memiliki keanekaragaman jenis yang tinggi, jika disusun oleh banyak jenis, sebaliknya komunitas tumbuhan paku memiliki keanekaragaman jenis yang rendah, jika disusun oleh sedikit jenis (Soegianto 1994 dalam Melsasail 2016). Odum (1995) menyatakan bahwa keanekaragaman jenis memiliki sejumlah komponen yaitu indeks keanekaragaman, indeks kemerataan, kerapatan, dominansi, frekuensi kehadiran, dan nilai penting.

Kusu-Kusu dan Soya merupakan dua desa yang terletak di Kecamatan Sirimau Kota Ambon. Berdasarkan survei, desa Kusu-Kusu dan desa Soya memiliki keanekaragaman jenis tumbuhan paku yang tinggi. Akan tetapi keberadaannya mulai terancam akibat kerusakan lingkungan, seperti tumbuhan paku yang hidup sebagai epifit kelangsungan hidupnya tergantung pada pohon tempat hidupnya, sementara banyak pohon-pohon yang ditebang oleh masyarakat untuk berbagai keperluan. Selain itu juga, banyak habitat tumbuhan paku yang sekarang sudah diubah menjadi tempat tinggal masyarakat.

Manfaat tumbuhan paku yaitu jenis Azolla pinnta yang bersimbosis dengan Anabaena azollae dapat di jadikan pupuk hijau karena dapat mengikat nitrogen bebas dari udara. Jenis Marsilea crenata (daun semanggi) dapat di jadikan sayuran. Selain itu juga, tumbuhan paku ada yang dijadikan bahan obat-obatan seperti Lycopodium clavatum dan Aspidium filix (Sastrapradja $d k k, 2002)$.

Sejauh ini, penelitian tentang struktur komunitas tumbuhan paku di desa KusuKusu dan desa Soya masih jarang dilakukan. Melihat hal tersebut, maka perlu dilakukan penelitian ini tentang struktur komunitas tumbuhan Paku (Pteridophyta) di Kawasan Hutan Kusu-Kusu Kecamatan Nusaniwe dan Soya Kecamatan Sirimau Kota Ambon sebagai Sumbangan IImiah bagi Mata Kuliah Ekologi Tumbuhan.

Tujuan penelitian adalah untuk mengetahui jenis-jenis, nilai indeks keanekaragaman dan indeks kemerataan, nilai kerapatan, dominansi, frekuensi kehadiran, dan nilai penting jenis tumbuhan paku (Pteridophyta) di desa Kusu-Kusu dan desa Soya Kecamatan Sirimau Kota Ambon serta mengetahui implikasi dari hasil penelitian dalam pembelajaran Ekologi Tumbuhan. 


\section{MATERIAL DAN METODE}

Tipe penelitian ini merupakan penelitian deskriptif kuantitatif untuk mengungkapkan informasi tentang struktur komunitas tumbuhan paku. Pengumpulan data dengan menggunakan metode transek berpetak Desa Kusu-Kusu dan Desa Soya. Penelitian ini berlangsung pada tanggal 18 Juli 2018 18 Agustus 2018.,

Populasi dalam penelitian ini adalah semua jenis tumbuhan paku (Pteridophyta) yang terdapat di Kawasan Hutan KusuKusu Kecamatan Nusaniwe dan Soya Kecamatan Sirimau Kota Ambon. Sampel dalam penelitian ini adalah jenis tumbuhan paku (Pteridophyta) yang terdapat dalam petak.

Tahap persiapan yang perlu dilakukan oleh peneliti sebelum melaksanakan penelitian adalah melakukan studi pendahuluan (observasi) dan komunikasi dengan masyarakat setempat untuk mengetahui keadaan alam dari lokasi penelitian. Tahap pelaksanaan bermula dari penentuan lokasi. Daerah yang dipilih sebagai lokasi penelitian adalah pada Kawasan Hutan Kusu-Kusu (Stasitun I) dan Kawasan Hutan Soya (Stasiun II). Data yang digunakan dalam penelitian ini adalah data struktur komunitas (indeks keanekaragaman, indeks kemerataan, kerapatan, kerapatan relatif, dominansi, dominansi relatif, frekuensi kehadiran, frekuensi kehadiran relatif, dan indeks nilai penting) tumbuhan paku.

\section{Pengambilan Sampel}

1. Buat 3 buah transek pada setiap stasiun penelitian yang diletakan pada jenis tumbuhan paku (Pteridophyta).

2. Pada masing-masing transek diletakan petak pengamatan dengan ukuran $1 \times 1$ meter sebanyak 10 buah petak yang jaraknya $10 \mathrm{~m}$ pada jenis tumbuhan paku (Pteridophyta).

3. Jenis tumbuhan paku (Pteridophyta) yang terdapat dalam setiap petak pengamatan pada hutan kusu-kusu maupun hutan soya diidentifikasi dan dihitung jumlah spesiesnya..

4. Data jumlah spesies tumbuhan paku (Pteridophyta) akan digunakan untuk menghitung struktur komunitas (indeks

5. keanekaragaman, indeks kemerataan, kerapatan, kerapatan relatif, dominansi, dominansi relatif, frekuensi kehadiran, frekuensi kehadiran relatif, dan indeks nilai penting) tumbuhan paku (Pteridophyta)

6. Makroalga yang tidak teridentifikasi di lokasi penelitian, kemudian dimasukan dalam plastik sampel untuk diidentifikasi lanjut

Indeks keanekaragaman $\left(H^{\prime}\right)$ jenis dapat dihitung dengan menggunakan indeks diversitas menurut Shannon-Wiener sebagai berikut.

$$
H^{\prime}=-\left(\sum P i \ln P i\right) \text { dimana } P i=\frac{n i}{N}
$$

Keterangan:

$H^{\prime}=$ Indeks keanekaragaman jenis

$P i=$ Probalitas spesies ke-i

$n i=$ Jumlah individu spesies ke-i

$N=$ Jumlah total spesies

In $=$ Logaritma nature

$\Sigma=$ Jumlah spesies individu

Dengan kriteria keanekaragaman jenis sebagai berikut: jika $H^{\prime}>3,3$, maka keanekaragaman jenis tinggi, jika 1,3< $<H^{\prime}<$ 3,3 , maka keanekaragaman jenis sedang, dan jika $H^{\prime}<1,3$, maka keanekaragaman jenis rendah

$K r i=$ Kerapatan relatif individu (\%)

$K L R i=$ Kelimpahan relatif individu (\%)

Fri $=$ Frekuensi kehadiran relatif individu (\%).

Indeks kemerataan $(E)$ jenis dapat dihitung dengan menggunakan indeks kemerataan dengan rumus sebagai berikut. $E=\frac{H^{\prime}}{\ln S}$

Keterangan:

$E=$ Indeks kemerataan

$H^{\prime}=$ Indeks keanekaragaman

$S=$ Jumlah total spesies

Dengan kriteria indeks kemerataan sebagai berikut: jika $0,75<E<1,00$, maka kemerataan stabil, jika $0,50<E<0,75$, maka kemerataan tidak stabil, dan jika $0,00<E<$ 0,50 , maka kemerataan tertekan.

Rumus untuk menghitung kerapatan (Ki) adalah sebagai berikut (Krebs, 1978). $\boldsymbol{K} \boldsymbol{i}=\frac{\boldsymbol{n i}}{\boldsymbol{A}}$

Keterangan:

$K i=$ Kerapatan individu spesie ke-i (ind $/ \mathrm{m}^{2}$ )

$n i=$ Jumlah individu spesies ke-i (individu)

$A=$ Luas area pengambilan sampel $\left(\mathrm{m}^{2}\right)$ 
Rumus untuk menghitung kerapatan relative $(K R i)$ adalah sebagai berikut (Krebs, 1978).

$K R i=\frac{K i}{\sum K} \times 100$

Keterangan:

$K R i=$ Kerapatan relatif spesies ke-i $(\%)$

$K i=$ Kerapatan individu sepsies ke-I (ind $/ \mathrm{m}^{2}$ )

$\sum K=$ Jumlah kerapatan semua individu

Dominansi $(D i)$ dihitung berdasarkan dominansi Simpson (Simpson dominance) sebagai berikut.

$D i=\frac{\sum n i(n i-1)}{N(N-1)}$

Keterangan:

$D i=$ Dominansi individu spesie ke-i

$n i=$ Jumlah individu spesies ke-i

$N=$ Jumlah total spesies

Rumus untuk menghitung dominansi relative $(D R i)$ adalah sebagai berikut (Krebs, 1978).

$D R i=\frac{D i}{\sum D i} \times 100$

Keterangan:

$D \dot{r}=$ Dominansi relatif spesies ke-i (\%)

$D i=$ Dominansi individu sepsies ke-i (ind $/ \mathrm{m}^{2}$ )

$\sum D=$ Jumlah kelimpahan semua individu

Rumus untuk menghitung frekuensi kehadiran (Fi) adalah sebagai berikut (Krebs, 1978).

$F i=\frac{J i}{K}$

Tabel 1. Jenis-Jenis Tumbuhan Paku (Pteridophyta) yang Terdapat di Kawasan Hutan Kusu-Kusu Kecamatan Nusaniwe dan Kawasan Hutan Soya Kecamatan Sirimau Kota Ambon.

\section{No Jenis Tumbuhan Paku}

\section{Kawasan Hutan Kusu-Kusu}

Kawasan Hutan

Soya

\begin{tabular}{llll}
\hline 1 & Adiantum caudatum & $\sqrt{ }$ & $\sqrt{ }$ \\
\hline 2 & Arachnoides hanaffii & - & $\sqrt{ }$ \\
\hline 3 & Athyrium esculenta & - & $\sqrt{ }$ \\
\hline 4 & Lycopodium mucronata & - & $\sqrt{ }$ \\
\hline 5 & Cibotium baranetz & - & $\sqrt{ }$ \\
\hline 6 & Christella parasitica & $\sqrt{ }$ & - \\
\hline 7 & Davallia denticulate & $\sqrt{ }$ & $\sqrt{ }$ \\
\hline 8 & Davallia trichomanoides & $\sqrt{ }$ & \\
\hline
\end{tabular}

Keterangan:

$F i=$ Frekuensi kehadiran individu spesies ke-i

$J i=$ Jumlah petak pengamatan terdapat induvidu spesies ke-i

$K=$ Jumlah semua petak pengamatan yang dibuat.

Rumus untuk menghitung frekuensi kehadiran relative (FRi) adalah sebagai berikut (Krebs, 1978).

$F R i=\frac{F i}{\sum F} \times 100 \%$

Keterangan:

$F r i=$ Frekuensi kehadiran relatif spesies

$F i=$ Frekuensi kehadiran individu individu.

Rumus untuk menghitung indeks nilai penting (INP) adalah sebagai berikut (Brower et al., 1990).

Keterangan:

$I N P=$ Indeks nilai penting

$K R i=$ Kerapatan relatif $(\%)$

$D R=$ Dominansi relatif $(\%)$

$F R i=$ Frekuensi kehadiran relatif $(\%)$

\section{HASIL DAN PEMBAHASAN}

(Pteridophyta) yang terdapat di kawasan hutan kusu-kusu kecamatan nusaniwe dan kawasan hutan Soya Kecamatan Sirimau Kota Ambon dapat dilihat pada tabel berikut. $\sum F=$ Jumlah frekuensi kehadiran semua

Lokasi Penelitian 


\begin{tabular}{|c|c|c|c|}
\hline 9 & Drymoglosum piloselloides & - & $\sqrt{ }$ \\
\hline 10 & Drynaria rigidula & $\sqrt{ }$ & $\sqrt{ }$ \\
\hline 11 & Drynaria sparsisora & $\sqrt{ }$ & $\sqrt{ }$ \\
\hline 12 & Gleichenia linearis & - & $\sqrt{ }$ \\
\hline 13 & Gleichenia hipsida & - & $\sqrt{ }$ \\
\hline 14 & Phymatodes scolopendria & - & $\sqrt{ }$ \\
\hline 15 & Polystichum adiantiforme & - & $\sqrt{ }$ \\
\hline 16 & Pteridium aquilinimum & $\sqrt{ }$ & $\sqrt{ }$ \\
\hline 17 & Pyrosia stigmosa & $\sqrt{ }$ & - \\
\hline 18 & Selaginella intermedia & $\sqrt{ }$ & $\sqrt{ }$ \\
\hline 19 & Tectaria crenata & - & $\sqrt{ }$ \\
\hline 20 & Thelypteris palustris & - & $\sqrt{ }$ \\
\hline 21 & Tricomones caudate & - & $\sqrt{ }$ \\
\hline 22 & Tricomones teysmanii & $\sqrt{ }$ & $\sqrt{ }$ \\
\hline
\end{tabular}

Keterangan: $(\sqrt{ })$ : Ada $\quad(-)$ : Tidak ada

Berdasarkan hasil indentifikasi jenisjenis tumbuhan paku yang ditemukan di kawasan hutan Kusu-Kusu sebanyak 10 jenis dan kawasan Soya sebanyak 20 jenis. Secara keseluruhan jenis tumbuhan paku yang ditemukan di kedua lokasi penelitian tersebut dikelompokan menjadi 2 kelas yaitu Filicinae/Pteropsida (paku sejati) dan Lycopodiinae (paku kawat). Kelas Filicinae/Pteropsida memiliki jumlah jenis yang lebih banyak, baik pada kawasan hutan Kusu-Kusu (8 jenis), dan kawasan hutan Soya (13 jenis). Adapun kelas Lycopodiinae memiliki jumlah jenis yang lebih sedikit, baik pada kawasan hutan Kusu-Kusu (2 jenis), dan kawasan hutan Soya (7 jenis).

Musriadi dkk (2017) menyatakan bahwa di kawasan Tahura Pocut Meurah Intan Kabupaten Aceh Besar, menemukan sebanyak 19 jenis tumbuhan paku yang semuanya berasal dari kelas Filicinae/Pteropsida. Miftakhul dkk., (2015) di Lumajang, menemukan sebanyak 31 jenis tumbuhan paku, yang terdiri dari kelas Filicinae/Pteropsida sebanyak 28 jenis, kelas Lycopodiinae sebanyak 2 jenis, dan kelas Psilophytinae sebanyak 1 jenis.

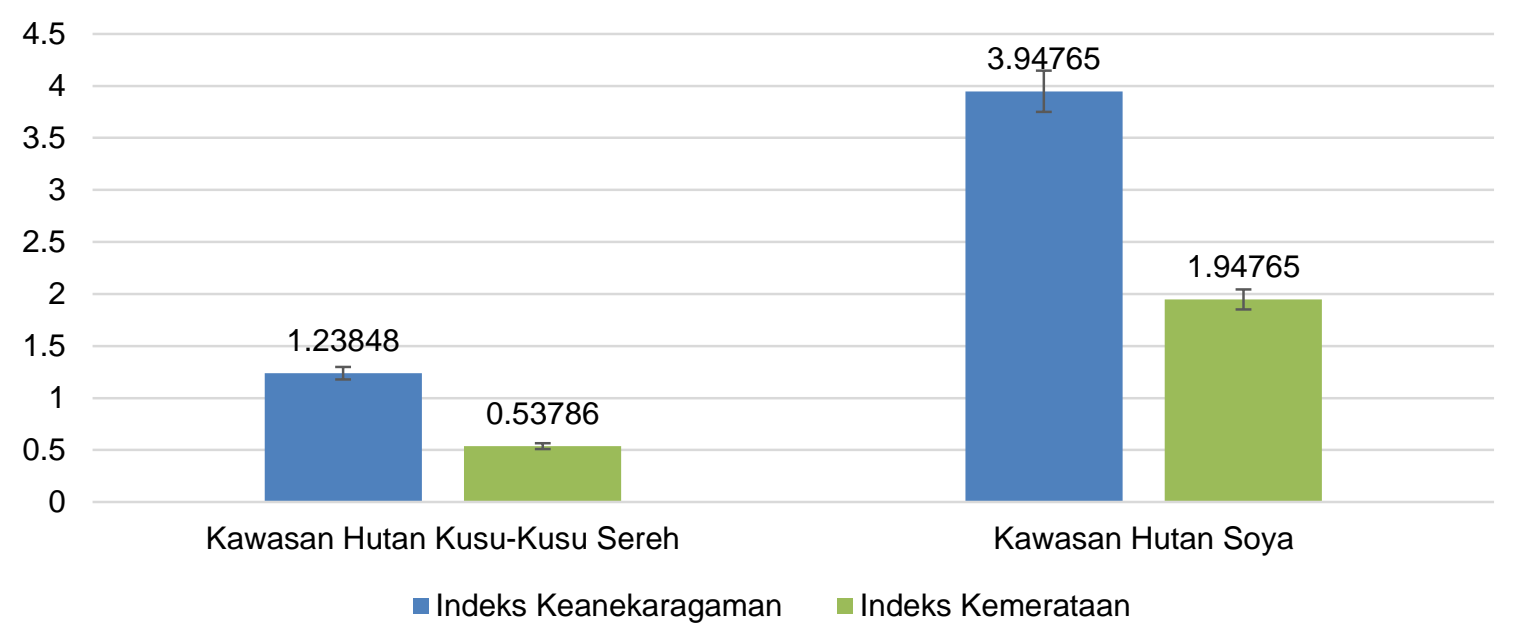

Grafik 1. Nilai Indeks Keanekaragaman dan Indeks Kemerataan Jenis Tumbuhan Paku.

Hasil perhitungan nilai indeks keanekaragaman jenis tumbuhan paku di kawasan hutan Kusu-Kusu Kecamatan Nusaniwe sebesar 1,23848 dengan jumlah jenis 10 dan jumlah total individu 1.713.
Nilai indeks keanekaragaman jenis tumbuhan paku di kawasan hutan Soya Kecamatan Sirimau sebesar 3,94765 dengan jumlah jenis 20 dan jumlah total individu 3.856 . 
Hasil perhitungan nilai indeks kemerataan jenis tumbuhan paku di kawasan hutan Kusu-Kusu sebesar 0,53786 . Nilai indeks kemerataan jenis tumbuhan paku pada kawasan hutan Soya sebesar 1,94765. Soegianto (1994) dalam Melsasail (2016) menjelaskan bahwa keanekaragaman berbanding lurus dengan kemerataan. Jika keanekaragaman jenis tinggi, maka kemerataannya stabil, sebaliknya jika keanekaragaman jenis rendah, maka kemerataan tidak stabil.

Kawasan hutan Soya memiliki nilai keanekaragaman jenis tumbuhan paku yang tinggi $(3,94765)$, dan kemerataannya stabil $(1,94765)$. Hal ini berbanding terbalik pada kawasan hutan Kusu-Kusu yang memiliki keanekaragaman jenis yang rendah $(1,23848)$, dan kemerataan tidak stabil $(0,53786)$.

Tabel 2. Rekapitulasi Nilai Kerapatan, Dominansi, Frekuensi Kehadiran, dan Nilai Penting Jenis Tumbuhan Paku di Kawasan Hutan Kusu-Kusu Kecamatan Nusaniwe Kota Ambon.

\begin{tabular}{|c|c|c|c|c|c|c|c|c|}
\hline No & $\begin{array}{c}\text { Jenis } \\
\text { Tumbuhan } \\
\text { Paku }\end{array}$ & $K i$ & Kri & Di & $D R i$ & $F i$ & Fri & INP \\
\hline 1 & $\begin{array}{l}\text { Adiantum } \\
\text { caudatum }\end{array}$ & 4,367 & 7,648 & 0,0058 & 5,220 & 0,767 & 9,315 & 22,183 \\
\hline 2 & $\begin{array}{l}\text { Christella } \\
\text { parasitica }\end{array}$ & 9,233 & 16,170 & 0,0260 & 23,402 & 1,000 & 12,144 & 51,716 \\
\hline 3 & $\begin{array}{l}\text { Davallia } \\
\text { denticulate }\end{array}$ & 6,033 & 10,565 & 0,0111 & 9,990 & 0,967 & 11,743 & 32,298 \\
\hline 4 & $\begin{array}{l}\text { Davallia } \\
\text { trichomanoides }\end{array}$ & 5,900 & 10,332 & 0,0106 & 9,540 & 0,867 & 10,529 & 30,401 \\
\hline 5 & Drynaria rigidula & 2,633 & 4,611 & 0,0021 & 1,890 & 0,433 & 5,258 & 11,759 \\
\hline 6 & $\begin{array}{l}\text { Drynaria } \\
\text { sparsisora }\end{array}$ & 2,733 & 4,786 & 0,0022 & 1,980 & 0,500 & 6,072 & 12,838 \\
\hline 7 & $\begin{array}{l}\text { Pteridium } \\
\text { aquilinium }\end{array}$ & 7,900 & 13,835 & 0,0190 & 17,101 & 1,000 & 12,144 & 43,080 \\
\hline 8 & $\begin{array}{l}\text { Pyrosia } \\
\text { stigmosa }\end{array}$ & 5,500 & 9,632 & 0,0092 & 8,280 & 0,833 & 10,116 & 28,028 \\
\hline 9 & $\begin{array}{l}\text { Selaginella } \\
\text { intermedia }\end{array}$ & 5,800 & 10,157 & 0,0102 & 9,180 & 0,867 & 10,529 & 29,866 \\
\hline 10 & $\begin{array}{l}\text { Trichomones } \\
\text { teysmanii }\end{array}$ & 7,000 & 12,259 & 0,0149 & 13,411 & 1,000 & 12,144 & 37,814 \\
\hline
\end{tabular}

Tabel 3. Rekapitulasi Nilai Kerapatan, Dominansi, Frekuensi Kehadiran, dan Nilai Penting Jenis Tumbuhan Paku di Kawasan Hutan Soya Kecamatan Sirimau Kota Ambon.

\begin{tabular}{llccccccc}
\hline No & $\begin{array}{c}\text { Jenis Tumbuhan } \\
\text { Paku }\end{array}$ & $\boldsymbol{K i}$ & $\boldsymbol{K R \boldsymbol { i }}$ & $\boldsymbol{D i}$ & $\boldsymbol{D r i}$ & $\boldsymbol{F i}$ & $\boldsymbol{F r i}$ & INP \\
\hline 1 & Adiantum caudatum & 5,067 & 3,942 & 0,0015 & 2,814 & 0,833 & 4,568 & 11,324 \\
\hline 2 & Arachnoides hanaffii & 4,433 & 3,448 & 0,0011 & 2,063 & 0,800 & 4,387 & 9,898 \\
\hline 3 & Athyrium esculenta & 4,033 & 3,137 & 0,0009 & 1,688 & 0,733 & 4,020 & 8,845 \\
\hline 4 & $\begin{array}{l}\text { Lycopodium } \\
\text { mucronata }\end{array}$ & 4,467 & 3,475 & 0,0011 & 2,063 & 0,733 & 4,020 & 9,558 \\
\hline 5 & Cibotium baranetz & 7,000 & 5,446 & 0,0029 & 5,440 & 1,000 & 5,484 & 15,370 \\
\hline 6 & Christella parasitica & 9,667 & 7,520 & 0,0056 & 13,506 & 1,000 & 5,484 & 23,510 \\
\hline 7 & $\begin{array}{l}\text { Davallia } \\
\text { trichomanoides }\end{array}$ & 5,967 & 4,642 & 0,0021 & 3,939 & 0,933 & 5,117 & 12,698 \\
\hline
\end{tabular}




\begin{tabular}{|c|c|c|c|c|c|c|c|c|}
\hline 8 & $\begin{array}{l}\text { Drymoglosum } \\
\text { piloselloides }\end{array}$ & 5,800 & 4,512 & 0,0020 & 3,752 & 0,933 & 5,117 & 12,381 \\
\hline 9 & Drynaria rigidula & 3,667 & 2,852 & 0,0008 & 1,500 & 0,667 & 3,658 & 8,010 \\
\hline 10 & Drynaria sparsisora & 3,967 & 3,086 & 0,0009 & 1,688 & 0,667 & 3,658 & 8,432 \\
\hline 11 & Gleichenia linearis & $\begin{array}{l}10,36 \\
7\end{array}$ & 8,065 & 0,0024 & 15,007 & 1,000 & 5,484 & 28,556 \\
\hline 12 & Gleichenia hipsida & 9,800 & 7,624 & 0,0057 & 13,694 & 1,000 & 5,484 & 21,802 \\
\hline 13 & $\begin{array}{l}\text { Phymatodes } \\
\text { scolopendria }\end{array}$ & 6,800 & 5,920 & 0,0027 & 5,065 & 1,000 & 5,484 & 16,469 \\
\hline 14 & $\begin{array}{l}\text { Polystichum } \\
\text { adiantiforme }\end{array}$ & 6,633 & 5,160 & 0,0026 & 4,878 & 1,000 & 5,484 & 14,522 \\
\hline 15 & $\begin{array}{l}\text { Pteridium } \\
\text { aquilinimum }\end{array}$ & 8,333 & 6,483 & 0,0041 & 10,692 & 1,000 & 5,484 & 21,659 \\
\hline 16 & $\begin{array}{l}\text { Selaginella } \\
\text { intermedia }\end{array}$ & 6,233 & 4,849 & 0,0023 & 4,315 & 1,000 & 5,484 & 13,648 \\
\hline 17 & Tectaria crenata & 6,300 & 4,901 & 0,0023 & 4,315 & 1,000 & 5,484 & 13,700 \\
\hline 18 & Thelypteris palustris & 7,733 & 6,016 & 0,0036 & 9,754 & 1,000 & 5,484 & 21,254 \\
\hline 19 & Tricomones caudata & 4,867 & 3,786 & 0,0014 & 2,626 & 0,933 & 5,117 & 11,529 \\
\hline 20 & $\begin{array}{l}\text { Tricomones } \\
\text { teysmanii }\end{array}$ & 7,400 & 5,757 & 0,0033 & 6,191 & 1,000 & 5,484 & 17,432 \\
\hline
\end{tabular}

Berdasarkan hasil perhitungan nilai kerapatan, dominansi, frekuensi kehadiran, dan nilai penting tumbuhan paku pada kawasan hutan Kusu-Kusu menunjukan bahwa jenis Christella parasitica memiliki nilai yang tertinggi, sedangkan jenis Drynaria rigidula memiliki nilai yang rendah. Adapun pada kawasan hutan Soya menunjukan bahwa jenis Gleichenia linearis memiliki nilai yang tertinggi, sedangkan jenis Drynaria rigidula memiliki nilai yang rendah.

Tingginya nilai kerapatan, dominansi, frekuensi kehadiran dan nilai penting tumbuhan paku jenis Christella parasitica pada kawasan hutan Kusu-Kusu dan Gleichenia linearis pada kawasan hutan Soya dikarenakan kedua jenis tumbuhan paku tersebut memiliki jumlah individu, total transek ditemukannya individu, dan jumlah petak ditemukannya individu yang lebih banyak. Adapun, rendahnya nilai kerapatan, dominansi, frekuensi kehadiran dan nilai penting tumbuhan paku jenis Drynaria rigidula pada kawasan hutan Kusu-Kusu dan Soya dikarenakan jenis tumbuhan paku tersebut memiliki jumlah individu, total transek ditemukannya individu, dan jumlah petak ditemukannya individu yang lebih sedikit.

Soegianto (1994) dalam Melsasail (2016) menjelaskan bahwa kerapatan dan kelimpahan ditentukan oleh banyaknya jumlah individu. Semakin banyak jumlah individu, maka semakin tinggi nilai kerapatan dan dominansinya, sebaliknya semakin sedikit jumlah individu, maka semakin rendah nilai kerapatan dan dominansinya. Individu dengan nilai kerapatan dan dominansi yang tinggi menunjukan bahwa individu tersebut memiliki kehadiran dalam jumlah yang banyak, sebaliknya individu dengan nilai kerapatan dan dominansi yang rendah menunjukan bahwa individu tersebut memiliki kehadiran yang sedikit. Berdasarkan hal tersebut, dapat disimpulkan bahwa individu yang memiliki nilai kerapatan, dan frekuensi kehadiran yang tinggi, maka akan memiliki nilai penting yang tinggi juga. $\mathrm{Hal}$ ini dikarenakan nilai penting didapat dari hasil penjumlahan kerapatan relatif, dominansi relatif, dan frekuensi kehadiran relatif.

\section{KESIMPULAN}

Tumbuhan paku yang ditemukan di kawasan hutan Kusu-Kusu Sereh Kecamatan Nusaniwe sebanyak 10 jenis, sedangkan di kawasan hutan Soya Kecamatan Sirimau sebanyak 20 jenis.

Nilai keanekaragaman jenis tumbuhan paku di kawasan hutan Kusu-Kusu Sereh Kecamatan Nusaniwe sebesar 1,2848 (tergolong rendah), sedangkan di kawasan 
hutan Soya Kecamatan Sirimau sebesar 3,94765 (tergolong tinggi). Nilai kemerataan jenis tumbuhan paku di kawasan hutan Kusu-Kusu Sereh Kecamatan Nusaniwe sebesar 0,53786 (tergolong tidak stabil), sedangkan di kawasan hutan Soya Kecamatan Sirimau sebesar 1,94765 (tergolong stabil).

Tumbuhan paku jenis Christella parasitica memiliki nilai kerapatan sebesar 9,233, dominansi sebesar 0,0260, frekuensi kehadiran sebesar 1,000 dan nilai penting sebesar 51,716 tertinggi di kawasan hutan Kusu-Kusu Sereh Kecamatan Nusaniwe. Tumbuhan paku jenis Gleichenia linearis memiliki nilai kerapatan sebesar 10,367, dominansi sebesar 0,0064, frekuensi kehadiran sebesar 1,000 dan nilai penting sebesar 26,556 tertinggi di kawasan hutan Soya Kecamatan Sirimau.

\section{DAFTAR PUSTAKA}

Brower, J. E., Zar, J. H \& Ende, C. N. V. 1990. Field and laboratory method for general ecology fourth edition. McGraw-Hill Publication. Boston, USA. $\mathrm{XI}+273 p$.

Kelurahan Kusu-Kusu Sereh. 2018. Profil Desa/Negeri Kusu-Kusu Sereh. Lembar Wawancara.

Krebs, C.J. 1978. Ecology of Experimental Analisys of Distribution and Abudance. Second edition. New York: Haperanda Row Publisher.

Melsasail, K. 2016. Struktur Komunitas dan Pengelolaan Makroalga (Seaweed) Di Peraiaran Pantai Pulau Nusalaut Kabupaten Maluku Tengah Serta Implikasinya Bagi Pembelajaran Ekologi Tumbuhan. Tesis tidak diterbitkan. Program Pascasarjana. Program Studi Pendidikan Biologi. Universitas Pattimura Ambon.

Miftakhul, J., Wahyu, P., dan Eko S. 2015. Identifikasi Pteridophyta di Piket Nol Pronojiwo Lumajang Sebagai Sumber Belajar Biologi. Jurnal Pendidikan Biologi Indonesia. ISSN: 2442-3750. Vol, 1. No. 1. Halaman 89-98.

Musriadi, Jailani, dan Armi. 2017. Identifikasi Tumbuhan Paku (Pteridophyta) Sebagai Bahan Ajar Botani Tumbuhan Rendah di Kawasan Tahura Pocut Meurah Intan Kabupaten
Aceh Besar. Jurnal Pendidikan Sains Universitas Muhammadyah Semarang. Vol. 5. No. 1. Maret 2017.

Odum, E. P. 1995. Dasar-dasar Ekologi. Jogjakarta: Gadjah Mada University Press.

Sandi, S. F., Pantiwati, Y., Hudha, A. M., dan Latifa, R. 2015. Keanekaragaman Jenis Tumbuhan Paku (Pteridophyta) Di Kawasan Air Terjun Lawean Sendang Kabupaten Tulungagung. Prosiding Seminar Nasional II Tahun 2016, Kerjasama Prodi Pendidikan Biologi dengan Pusat Studi Lingkungan dan Kependudukan (PSLK) Universitas Muhammadiyah Malang; Malang, 26 Maret 2016.

Sastrapradja, S., Afriastini, J. J., Durnaedi, D., DAN Widjaja, E. A. 2002. Jenis Paku Indonesia. Lembaga Biologi Nasional-LIPI Bogor, 129p.

Suraidi, Susanti, T., dan Amriyanto, R. 2012. Keanekaragaman Tumbuhan Paku (Pteridophyta) Di Taman Hutan Kenali Kota Jambi. Prosiding Semirata FMIPA Universitas Lampung.

Tjitrosoepomo, G. 2011. Taksnomi Tumbuhan. Yogyakarta: Gadjah Mada University Press

Yudianto, A., dan Suroso.2007. Petunjuk Praktikum Botani Cryptogamae. Bandung: Jurusan Pendidikan Biologi FPMIPA UPI. 